\title{
O Lado Sombrio da Força: A Má Liderança e suas Consequências para os Indivíduos e as Organizações
}

\section{The Dark Side of the Force: Bad Leadership and its Consequences for Individuals and Organizations}

\author{
Daniel Martins Abelha \\ Universidade Federal Rural do Rio de Janeiro - UFRRJ / FEA-USP \\ abelhadaniel@usp.br \\ Flavia Souza Costa Neves Cavazotte \\ IAG-PUC-Rio \\ flavia.cavazotte@iag.puc-rio.br \\ Jeane Rodrigues Lucena Niemeyer \\ PUC-Rio \\ lucenajeane@gmail.com \\ Otacílio Torres Villas Boas \\ Universidade Federal da Bahia -UFBA \\ otaciliotorres@hotmail.com
}

Submissão: 05/06/2019

Aprovação: 24/01/2020

\begin{abstract}
RESUMO
Diversas perspectivas no campo de estudos sobre a liderança se concentram na teorização sobre a liderança efetiva, isto é, sobre os fatores que favorecem a mobilização de grupos para realizações coletivas. No entanto, na prática, muitos indivíduos carecem desses atributos e, dadas suas limitações e vícios, alguns sequer deveriam estar em posições de liderança. Contribuindo para a compreensão desse fenômeno, esta pesquisa investigou a má liderança no ambiente corporativo brasileiro, a partir das experiências vivenciadas por 35 profissionais de diferentes setores e áreas de atuação. Com base nesses relatos e na aplicação da análise de conteúdo, foram derivados seis tipos de maus lideres: incompetente, omisso, inconsistente, rígido, abusivo e desleal. $\mathrm{O}$ estudo analisou as principais consequências da má liderança para os liderados, as equipes e as organizações, bem como as estratégias de reação mais frequentemente adotadas. $\mathrm{O}$ artigo discute as implicações teóricas e práticas dessas observações, apresentando uma agenda para pesquisas futuras.
\end{abstract}

Palavras-chave: Desempenho Organizacional. Liderança Destrutiva. Liderança Ética. Liderança Moral. Liderança Tóxica. 


\section{ABSTRACT}

Most perspectives in leadership studies focus on theorizations about effective leadership, on the factors that potentialize the mobilization of groups toward collective endeavors. However, in practice, many individuals lack these attributes. Contributing to the understanding of this phenomenon, this research investigates bad leadership in the brazilian corporate environment, grounded on the experiences shared by 35 professionals from different sectors and areas of activity. Based on these reports and the application of content analysis, six types of bad leadership were derived: incompetent, omissive, inconsistent, rigid, abusive and unfair. The study examines the main consequences of bad leadership for followers, teams and organizations, as well as the reaction strategies most frequently adopted. The article discusses the theoretical and practical implications of these observations, presenting an agenda for future research.

Keywords: Destructive Leadership. Ethical Leadership. Moral Leadership. Organizational Performance. Toxic Leadership.

\section{Introdução}

Líderes são frequentemente descritos na literatura como indivíduos visionários, capazes de criar organizações grandiosas e feitas para durar, de mobilizar importantes realizações coletivas e de promover mudanças que geram progresso nas empresas e na sociedade (YUKL, 2002; GEORGE et al., 2007). Revisões de literatura sugerem que as perspectivas sobre a liderança tipicamente atentam para as virtudes e capacidades necessárias aos líderes para o alcance desses objetivos (DIHN et al., 2014). Os resultados dessas sínteses colocam como as teorias mais influentes sobre o tema, as perspectivas carismática e transformacional, descrevem os líderes eficazes como sendo indivíduos inspiradores, que estimulam o engajamento de seus liderados e estão atentos às suas necessidades particulares (AVOLIO, 1999; BASS e AVOLIO, 1990). Embora algumas das perspectivas que dominam o campo, como a teoria leader-member exchange (LMX), assumam que nem todas as relações de um líder com seus liderados são igualmente positivas (GRAEN e UHL-BIEN, 1995), essas perspectivas propõem como ideal da liderança relações recíprocas de suporte, respeito e confiança. Abordagens mais recentes, como a teoria da liderança autêntica, enfatizam também as virtudes morais dos bons líderes, que se orientariam pela transparência, por princípios éticos sólidos, e seriam equilibrados e conscientes de suas limitações (GARDNER et al., 2005). Nota-se, portanto, que boa parte das teorias mais amplamente investigadas no campo (DIHN et al., 2014), ressaltam atributos inerentemente positivos, tanto no que diz respeito às competências e virtudes dos líderes, quanto à qualidade das relações que devem estabelecer com seu grupo (LUCENA e CAVAZOTTE, 2016).

Na prática, contudo, alguns indivíduos que exercem papéis de liderança não apenas carecem de competências pessoais desejáveis para tal, mas também exibem vícios em sua conduta (HARMS et al., 2018; WATKINS, FEHR e HE, 2019). Embora o poder destrutivo das ações desses líderes tenha um amplo alcance e, eventualmente, suas consequências sejam irreparáveis (CIULLA, 2004), a má liderança tem recebido relativamente pouca atenção no campo de estudos sobre o tema (CRAIG e KAISER, 2013; O'REILLY III, DOERR e CHATMAN, 2018).

Este estudo busca aprofundar o conhecimento sobre a liderança tóxica por meio de uma pesquisa de campo realizada com profissionais de diferentes setores, áreas de negócio e níveis organizacionais, que experimentam diferentes manifestações da má liderança nas 
organizações. As experiências desses profissionais com maus líderes serviram como base para o alcance de três objetivos específicos: 1) melhor caracterizar as dimensões da má liderança mais frequentemente observadas no contexto brasileiro; 2) analisar os principais impactos da má liderança no ambiente de trabalho; e 3) analisar as principais estratégias adotadas pelos participantes para lidar com a liderança tóxica.

Esta pesquisa contribui para a literatura sobre liderança, primeiramente, ao investigar um ângulo pouco conhecido, mas particularmente relevante do fenômeno, dado seu alcance e consequências destrutivas. Do mesmo modo que estudos sobre a liderança efetiva são essenciais para promovê-la, a pesquisa sobre a má liderança é essencial para compreender suas origens e possibilitar sua prevenção (KELLERMAN, 2013). Através da pesquisa aplicada, este estudo estabelece uma base para o aprofundamento teórico-conceitual sobre o tema, o que favorece sua investigação continuada em pesquisas empíricas em organizações públicas e privadas. Em particular, este trabalho também contribui para um melhor entendimento sobre a má liderança no Brasil, ao identificar as diferentes dimensões e consequências da má liderança nesse contexto. Como enfatizado por Harms et al. (2018), expressões da liderança tóxica são um fenômeno sujeito à influência de fatores socioculturais, o que torna ainda mais relevante sua investigação em contextos sociais específicos, particularmente num ambiente onde a produção de conhecimento sobre o tema ainda é escassa, como no Brasil (ANDRADE et al., 2019; ABELHA e CAVAZOTTE, 2016) buscas por artigos em bases científicas nacionais, como SCIELO e SPELL, publicados nesta década em periódicos brasileiros denotam a considerável lacuna sobre o tema existente no cenário nacional. Adicionalmente, este estudo contribui para o conhecimento ao analisar aproximações e distanciamentos entre as proposições sobre o tema em estudos internacionais e as observações realizadas no contexto brasileiro, e assim desenvolver o conhecimento sobre o tema tal como este se manifesta no contexto local. Por fim, este trabalho também apresenta premissas úteis para apoiar a formação de lideranças e promover uma melhor qualificação de líderes, ao explicitar comportamentos indesejáveis, gerando também insumos para o desenvolvimento de políticas de prevenção e correção quando a liderança é desvirtuada pelas sombras da incompetência ou da imoralidade.

\section{Referencial Teórico}

\subsection{A Boa Liderança}

A literatura sobre liderança tem sido profusa em perspectivas que apontam as virtudes e as capacidades desejáveis nos bons líderes, bem como as qualidades positivas das relações de liderança ideais. A qualificação de um líder como "bom" permite que se estabeleça dois julgamentos distintos sobre suas ações: que estas são tecnicamente boas (efetivas para a consecução de objetivos coletivos) e que são moralmente boas (orientadas por princípios éticos) (CIULLA, 2004). Líderes efetivos deveriam, portanto, possuir habilidades para mobilizar e coordenar esforços e promover mudanças, mas também ser moralmente consistentes, isto é, orientar sua conduta por princípios éticos, tanto quanto aos fins que almejam quanto aos meios que adotam para alcançá-los.

As perspectivas contemporâneas sobre liderança têm tratado tanto a efetividade quanto a moralidade nesse processo. Enquanto alguns autores discorrem sobre aspectos instrumentais associados à efetividade dos líderes para exercer influência e sobre as vias através das quais líderes promovem atitudes e comportamentos produtivos, outros dão maior ênfase aos aspectos morais e éticos do processo de liderança, e discutem especificamente como e porque a conduta do líder deve se orientar por princípios elevados. As próximas seções apresentam as premissas das perspectivas que predominam no campo, de acordo com revisões sistemáticas 
da literatura (DIHN et al., 2014; TURANO e CAVAZOTTE, 2016), para fins de balizamento da discussão central a este trabalho.

\subsubsection{Perspectivas Teóricas Associadas à Liderança Efetiva}

A perspectiva da liderança transformacional diz respeito ao desempenho e também ao desenvolvimento do potencial dos seguidores (AVOLIO, 1999; BASS e AVOLIO, 1990). Bass (1985) ampliou o trabalho de Burns (1978), argumentando que o líder transformacional motiva seus seguidores a realizar mais do que o esperado deles: aumenta seu nível de consciência sobre a importância e o valor de objetivos específicos e idealizados, e motiva os seguidores para transcender seus interesses próprios em prol da equipe ou da organização (BASS, 1985; BASS e AVOLIO, 1993). Estes líderes seriam capazes de articular uma visão e inspirar seus liderados, de estar atentos às suas necessidades e motivações, e de ajudá-los a desenvolver seu potencial.

Líderes transformacionais são descritos como indivíduos capazes de comunicar uma visão de futuro para a organização, equipe de trabalho ou outra coletividade, apelando para ideias e valores, e inspirando o comprometimento de seus seguidores com essa visão (BASS, 1985; BURNS, 1978). Esses líderes estimulam seus liderados a pensar de maneira alternativa sobre problemas, e assim elevariam a qualidade de seus julgamentos e decisões. A perspectiva enfatiza a importância dos valores e crenças dos líderes, de seu senso de missão e propósito e sua habilidade para comunicar confiança e estimular intelectualmente o grupo. As pesquisas ratificam a influência positiva dos líderes transformacionais no desempenho de subordinados (LOWE, KREOCKE e SIVASUBRAMANIAM, 1996; CAVAZOTTE, MORENO e BERNARDO, 2013) e na eficácia organizacional (AVOLIO, BASS e JUNG, 1999; LOWE et al., 1996; CAVAZOTTE, MORENO e LASMAR, 2018).

Outra perspectiva que também enfatiza a importância de líderes estabelecerem relações de alta qualidade com seus seguidores é a teoria das trocas líder-seguidor (leadermember exchange theory - LMX). Segundo esta perspectiva, o líder estabelece diferentes relações com seus liderados de modo que há a existência de dois grupos diferentes que são formados em função da maior ou menor qualidade de suas relações com o líder, o in-group, cujos membros teriam papéis e responsabilidades expandidos em função da proximidade do líder, e o out-group, cujos membros se limitariam aos papéis e responsabilidades definidos em contrato formal de trabalho (GRAEN e UHL-BIEN, 1995; LIDEN, WAYNE e STILWELL, 1999).

A teoria parte do princípio de que as relações entre líder e seguidor se desenvolvem ao longo do tempo. Inicialmente, essas relações são regidas por regras contratuais, há baixa qualidade de trocas, e o seguidor obedece ao líder pela hierarquia. Posteriormente, o líder ofereceria ao liderado oportunidades para aprimorar as trocas profissionais, partilhando mais informações e recursos. Este seria um período de teste, no qual se verifica se o liderado está disposto a assumir mais papéis e responsabilidades, e se o líder está disposto a lhe fornecer mais desafios. Esse processo seria a base para a construção de uma relação de alta qualidade entre as partes. A relação pode evoluir ao nível de uma parceria, caracterizada por alto grau de confiança, reciprocidade, respeito e senso de obrigação mútua entre eles, assim se desdobrando em um relacionamento mais efetivo. A perspectiva reforça a importância da comunicação na liderança e da justiça no relacionamento entre o líder e seus seguidores, através do respeito e da criação de uma relação de confiança mútua. Quando os relacionamentos são de alta qualidade, os objetivos de líderes, seguidores e da organização são favorecidos (GRAEN e UHL-BIEN, 1995; LUCENA e CAVAZOTTE, 2016). 


\subsubsection{Perspectivas Teóricas Associadas à Liderança Moral}

Diante dos casos recentes de escândalos corporativos e de corrupção, que tiveram como consequência quedas de competitividade em organizações de diferentes setores (VALOR ECONÔMICO, 2019; EXAME, 2019), a transparência e a ética nas relações são assuntos que ganharam evidência na literatura sobre organizações e liderança (LUCENA e CAVAZOTTE, 2016; TURANO e CAVAZOTTE, 2016). Esta nova forma de liderar passou a ser demandada por uma sociedade cada vez mais cética e crítica com profissionais que se mostram negligentes e inescrupulosos perante seus stakeholders (TURANO e CAVAZOTTE, 2016). De maneira consciente, estes indivíduos buscam expor uma imagem que não está alinhada com suas ações diárias e, quando desmascarados, perdem a credibilidade profissional (CIULLA, 2004).

Os desafios contemporâneos de ordem política, econômica, social e ambiental também estimularam a discussão sobre os aspectos positivos e morais na literatura sobre liderança. Dentre alguns, destaca-se o seu potencial para a criação de laços de confiança e a prevenção de comportamentos antiéticos no cotidiano laboral. Além disto, a liderança baseada em princípios morais poderia facilitar a intermediação de conflitos e expectativas sociais, já que é orientada por valores coletivos, como justiça, integridade e honestidade (AVOLIO e GARDNER, 2005).

Segundo Lucena e Cavazotte (2016), bons líderes deveriam promover climas organizacionais éticos, caracterizados por altos padrões morais. Neste contexto, diversas teorias têm surgido na literatura na busca de se compreender o processo da liderança baseada em princípios morais (AVOLIO e GARDNER, 2005; TURANO e CAVAZOTTE, 2016). Dentre elas, destaca-se a teoria da liderança autêntica (GARDNER et al., 2005), que enfatiza a liderança moral a partir do foco no bem comum (AVOLIO et al., 2004; BASS e STEIDLMEIER, 1999).

O líder autêntico se caracteriza pela sua autoconsciência e por suas ações e relacionamentos autênticos. Segundo Luthans e Avolio (2003), líderes autênticos são guiados por valores explícitos e conscientes, e por um nível de integridade moral elevado. Eles enfatizariam os interesses coletivos de seu grupo ou organização, considerando aspectos morais, como fazer o que é certo e justo, de forma transparente. Líderes com forte integridade, se destacam por sua consistência interna, derivada de experiências emocionais e valores dignos, que os fazem agir com respeito aos interesses e direitos dos outros. Uma vez comprometidos com esses valores, esses líderes seriam mais consistentes e transparentes, seus pensamentos e sentimentos seriam coerentes com suas ações, o que geraria uma maior percepção de integridade e confiança. Dessa forma, líderes autênticos promoveriam um clima de trabalho baseado no acesso à informação, recursos e suporte, além de proporcionar aos seus liderados oportunidades de aprendizado e processos de desenvolvimento estruturados e justos. Essa teoria sugere que líderes devem criar e manter um clima que permita a ambos, líderes e seguidores, aprender e crescer de forma contínua (CAVAZOTTE, DUARTE e GOBBO, 2013; ESPER e CUNHA, 2015).

\subsection{A Má Liderança - O Lado Sombrio da Força}

Seria ingênuo assumir que todo indivíduo que atua em uma posição formal de liderança na estrutura de uma organização é um bom líder. A palavra liderança em si possui uma conotação positiva intrínseca, pois tanto na academia como na mídia de negócios, o pensamento sobre liderança acentua muito mais os aspectos positivos do processo do que os negativos (KELLERMAN, 2004). Assim, os aspectos negativos acabam sendo ignorados, ficando fora do foco de atenção dos estudos sobre o tema. No entanto, na última década houve um crescente reconhecimento entre os pesquisadores de que o comportamento destrutivo dos 
líderes é tão importante para uma organização quanto aqueles positivos e desejáveis mais comumente estudados (CRAIG e KAISER, 2013; O'REILLY III, DOERR e CHATMAN, 2018).

À luz do proposto por Ciulla (2004), Kellerman (2004) enfatiza duas categorias principais de má liderança: a ineficaz e a antiética. Na maioria dos casos de liderança ineficaz, faltam ao líder as capacidades e habilidades necessárias para analisar situações, tomar decisões e superar desafios. Suas estratégias são mal concebidas, seus planos mal executados, e eles falham em promover mudanças quando elas são necessárias. Já no caso de líderes antiéticos, estes falham ao distinguir o que é certo e o que é errado. Burns (1978) sugere como padrão de liderança ética os líderes que colocam as necessidades de seus seguidores à frente das suas, que são exemplos de virtudes pessoais como coragem e temperança, e que exercitam a liderança para o interesse do bem comum. Podemos assumir então que o líder imoral é aquele que apresenta padrões de comportamento que se opõem a essas características, que despreza as necessidades de seus liderados, é fraco e destemperado, e exercita a liderança colocando seus interesses pessoais a frente dos interesses coletivos.

Kellerman (2004) descreve sete tipos diferentes de maus líderes (Quadro 1). Os dois primeiros se referem ao líder ineficaz, enquanto os cinco últimos se referem ao líder antiético:

\begin{tabular}{|c|l|}
\hline Tipos & \multicolumn{1}{|c|}{ Descrição } \\
\hline Incompetente & $\begin{array}{l}\text { Falta ao líder vontade e/ou habilidade para sustentar ações eficazes. No que } \\
\text { diz respeito aos desafios da liderança, ele não cria mudanças positivas. }\end{array}$ \\
\hline Rígido & $\begin{array}{l}\text { O líder é rígido e inflexível. Embora possa ser competente, ele é incapaz ou } \\
\text { relutante ao se adaptar a novas ideias, novas informações ou mudanças. }\end{array}$ \\
\hline Destemperado & Falta ao líder autocontrole. Ele é dado a excessos. \\
\hline Insensível & $\begin{array}{l}\text { O líder é insensível e cruel. Ignora as necessidades e desejos da maioria dos } \\
\text { membros do grupo ou organização. }\end{array}$ \\
\hline Corrupto & $\begin{array}{l}\text { O líder mente, trapaceia ou rouba. Num grau que ultrapassa a norma, ele } \\
\text { coloca interesses pessoais à frente do interesse público. }\end{array}$ \\
\hline Insular & $\begin{array}{l}\text { O líder desconsidera a saúde e o bem-estar daqueles que estão fora do grupo } \\
\text { ou organização pela qual é diretamente responsável. }\end{array}$ \\
\hline Perverso & $\begin{array}{l}\text { O líder comete atrocidades. Ele usa a dor como instrumento de poder. O } \\
\text { dano feito aos outros é severo. Ele pode ser físico, psicológico ou ambos. }\end{array}$ \\
\hline
\end{tabular}

Quadro1. Tipos de Má Liderança segundo Kellerman.

Fonte: Adaptado de Kellerman (2004).

No contexto internacional, sínteses sobre a pesquisa acerca da má liderança observam que os estudos sobre o tema são mais escassos do que a vertente que investiga a liderança virtuosa (CRAIG e KAISER, 2013; DIHN et al., 2014). Diferentes conceitos foram propostos, como a liderança negligente ou laissez-faire, o lado sombrio do carisma, a supervisão abusiva e o narcisismo destrutivo (HARMS et al., 2018; WATKINS, FEHR e HE, 2019), sem que haja, contudo, uma articulação sistemática entre essas concepções (CRAIG e KAISER, 2013). No contexto nacional, a escassez de estudos sobre a má liderança é notável: buscas em bases de dados nacionais, como SCIELO e SPELL, com os termos "má liderança", "liderança tóxica", "liderança destrutiva" e "liderança abusiva" nos últimos dez anos geram resultados nulos para publicações em periódicos, e alguns poucos artigos apresentados em congressos (ANDRADE et al., 2019; ABELHA e CAVAZOTTE, 2016).

A liderança negligente ou laissez-faire está associada à passividade, à falta de atuação por parte dos líderes (CRAIG e KAISER, 2013). Estudos na área indicam que a negligência do líder está negativamente relacionada à sua efetividade, à satisfação de liderados com o 
trabalho e com sua chefia (JUDGE e PICCOLO, 2004), e que esse tipo de liderança tem associação com conflito e ambiguidade nas tarefas (SKOGSTAD et al., 2007).

O carisma dos líderes é geralmente considerado uma alavanca de mobilização e resultados (HOUSE, SPANGLER e WOYCKE, 1991), mas também pode ser utilizado de forma negativa, quando o líder se aproveita do seu prestígio para obter vantagens pessoais, deixando de lado os interesses do grupo ou organização (CRAIG e KAISER, 2013). Com frequência o fascínio por líderes carismáticos e sua natureza sedutora obscurecem a capacidade de fazer juízos críticos sobre suas ações e intenções (CIULLA, 2004; ABELHA e CAVAZOTTE, 2016).

A supervisão abusiva é definida por Tepper (2000) como aquela que apresenta, de forma recorrente, hostilidades verbais e não verbais, incluindo agressões físicas. Supervisores abusivos podem ser ofensivos, ridicularizar e diminuir seus subordinados. Estudos sobre supervisão abusiva têm sido conduzidos no ambiente corporativo e educacional. Pesquisas na área apontam que a supervisão abusiva está negativamente relacionada à satisfação no trabalho (TEPPER, 2000) e com o comprometimento com a organização (DUFFY, GANSTER e PAGON, 2002), e positivamente relacionada com a intenção de sair da empresa (TEPPER, 2000), a resistência a instruções (TEPPER et al., 2001), e aos comportamentos contraprodutivos em relação ao supervisor (INNESS, BARLING e TURNER, 2005; LIANG et al., 2018; LEE, KIM e YUN, 2018), à organização e aos colegas (MITCHELL e AMBROSE, 2007).

Os líderes narcisistas costumam ter uma visão exagerada de seu próprio valor, mas como são também destemidos e agressivos, eles conseguem atrair atenção e ser vistos como líderes efetivos. Porém, há um outro lado em sua personalidade - sua arrogância, egocentrismo e hostilidade podem levá-los a verem os outros como inferiores e a menosprezar seus direitos e bem-estar (ROSENTHAL e PITTINSKY, 2006; O'REILLY III, DOERR e CHATMAN, 2018). Um dos efeitos causados pelo narcisismo destrutivo é o afastamento dos melhores funcionários, pois líderes narcisistas não toleram o sucesso do funcionário que ameaça se destacar mais do que eles (LUBIT, 2002). Além de perdas em eficiência, seus seguidores ficam desmotivados e passam a concentrar energia na sua sobrevivência. $O$ narcisismo destrutivo aumenta a exposição da empresa a processos judiciais (O'REILLY III, DOERR e CHATMAN, 2018), e pode até levar a organização à falência, se o líder narcisista estiver em um cargo de alto escalão (LUBIT, 2002).

O foco no líder é comum nas pesquisas sobre má liderança (KELLERMAN, 2004), mas os resultados destrutivos para as organizações também podem ter como coadjuvantes características de seguidores e do contexto (SHARMA, 2018). Kellerman (2004) acrescenta que o tipo de liderança emergente dependerá não apenas dos membros do grupo, mas também da natureza da tarefa em questão. No entanto, segundo a autora, líderes se comportam mal, principalmente, por serem quem são e pelo que querem alcançar, em referência a sua ganância por poder. O conceito da "tríade escura" (dark triad) é apresentado como um perfil personológico que reúne traços de narcisismo, maquiavelianismo e psicopatia (PALHUS e WILLIAMS, 2002), e que estaria associado a um padrão de comportamento interpessoal insensível e manipulador.

Segundo Krasikova, Green e Lebreton (2013), os principais resultados da liderança tóxica são consequências negativas para a própria organização, como, por exemplo, ineficiência, fracasso no alcance de metas e recorrência de problemas legais. Naturalmente, a má liderança também traz consequências negativas para os seguidores, como déficits em seu bem-estar físico e psicológico, queda de produtividade e insatisfação (KRASIKOVA, GREEN e LEBRETON, 2013). A má liderança está associada à falta de motivação e alta rotatividade de empregados, ao comprometimento dos interesses legítimos da organização, 
bem como a prejuízos no compartilhamento do conhecimento e postura colaborativa nas organizações (HARMS et al., 2017; LEE, KIM e YUN, 2018).

\section{Método de Investigação}

Uma vez que este estudo é de natureza exploratória e a compreensão do fenômeno de ordem subjetiva, foi adotado o método qualitativo com o uso de entrevistas, face à sua melhor adequação a estudos dessa natureza (CRESWELL, 2010). De acordo com Pratt (2009), a pesquisa qualitativa deve ser aplicada quando o foco da investigação está em "como" ou "por que" um fenômeno ocorre, quando se buscar examinar e articular processos ou quando se busca compreender um fenômeno a partir das perspectivas daqueles que o vivenciam. Este trabalho tem como principal objetivo investigar a má liderança a partir da percepção de profissionais vinculados a organizações públicas e privadas no contexto brasileiro. Assim, a escolha pelo método se justifica no fato dessa abordagem permitir a compreensão das manifestações da má liderança a partir das experiências vividas no ambiente organizacional local, facultando dessa forma um tratamento do fenômeno livre dos padrões e conceitos desenvolvidos na literatura internacional e dando margem à sua observação pela ótica dos sujeitos que vivenciam a má liderança no contexto organizacional brasileiro.

Neste estudo, a coleta de dados qualitativos se deu através de entrevistas. O método permite a geração e dados empíricos a partir de conversas guiadas semiformais com pessoas que produzem narrativas acerca do fenômeno de interesse a partir de suas experiências e percepções (SILVERMAN, 2006; MISHLER, 1986), assim privilegiando a subjetividade individual. A análise dos dados produzidos pelas entrevistas se baseou nos princípios da análise de conteúdo, instrumento metodológico aplicado na análise dos dados textuais gerados a partir dos relatos de experiências dos participantes da pesquisa, buscando compreender os elementos centrais da comunicação, bem como do seu significado, que nem sempre é manifestado e não é único (BARDIN, 2011). A análise de conteúdo envolve um conjunto de técnicas que investigam as comunicações através de procedimentos sistemáticos que permitem a inferência de conhecimentos. Nesta pesquisa, a análise seguiu as fases fundamentais previstas por Bardin (2011): a pré-análise, a exploração do material e o tratamento dos resultados (inferência e a interpretação). O resultado da análise de conteúdo se consolida na elaboração e definição de categorias síntese.

O recrutamento dos participantes foi realizado através da rede de relacionamentos dos pesquisadores, através de chamadas postadas em redes sociais, convidando pessoas que tivessem convivido com "maus líderes" para compartilhar suas experiências, com a garantia do anonimato. Nenhuma definição prévia sobre o que constituiria um mau líder foi apresentada, para evitar quaisquer vieses baseados nas experiências dos pesquisadores ou induzir o tipo de má liderança levantado. No entanto, tendo em vista o foco nas experiências de profissionais com maus líderes, foram utilizados como critérios para participar na pesquisa ter nível superior e ter pelo menos um ano de convívio com o mau líder. Os participantes responderam voluntariamente ao convite para participar da pesquisa e todos os relatos de indivíduos que tiveram contato com superiores considerados maus líderes foram considerados, respeitados os critérios para participação anteriormente mencionados.

No total, foram realizadas 35 entrevistas em profundidade com profissionais de diferentes segmentos, todos com no mínimo nível de instrução superior incompleto, empregados há no mínimo dois anos em organizações do Rio de Janeiro. Os participantes têm entre 21 e 51 anos, sendo 19 do sexo feminino e 16 do sexo masculino. Na ocasião das entrevistas, os participantes atuavam em empresas públicas e privadas, de múltiplos setores (comércio, serviços financeiros, serviços educacionais, energia, saúde, turismo, entre outros), e em diferentes áreas funcionais (operações, financeiro, marketing/comercial, recursos humanos, entre outros). De forma a preservar a identidade dos entrevistados, nenhum dado de 
caráter pessoal foi levantado. Embora os maus líderes descritos neste estudo sejam majoritariamente homens, aproximadamente $20 \%$ eram mulheres.

Entrevistas semiestruturadas foram realizadas a partir de um roteiro de perguntas relacionadas à liderança, sondando as experiências vividas pelo entrevistado, equipe e organização, e as estratégias adotadas para lidar com a situação. Com o consentimento dos participantes, as entrevistas foram gravadas e transcritas para posterior análise, resultando na identificação das características atribuídas aos líderes, que foram agrupadas em categorias temáticas, base para a consolidação das dimensões da má liderança apresentadas nesta pesquisa.

\section{Apresentação e Discussão dos Resultados}

A partir das falas dos participantes, foi possível observar que a sua percepção sobre a liderança pressupõe, em algum nível, uma quebra de expectativas acerca de como a liderança "deveria ser". A frustração com um líder em parte está associada a expectativas não correspondidas de que o líder apresente aquilo que se considera liderança eficaz. Três expectativas associadas à boa liderança, em particular, quando frustradas, evocaram reações negativas e a qualificação da liderança como má, negativa ou tóxica: (1) liderança pelo exemplo, (2) orientação sobre tarefas e resultados esperados, e (3) habilidades relacionais.

A liderança pelo exemplo está associada à expectativa de que o líder se comporte de forma coerente e alinhada com o que é esperado dos liderados:

“A empresa exige um horário da equipe, enquanto o líder faz seu próprio horário... ele tira um horário extenso para o almoço, mais de duas horas, pois precisa buscar os filhos na escola ou tratar de algum compromisso pessoal. Além de faltar bastante ao trabalho, sempre alegando alguma doença ou problema pessoal” (E19).

“[...] e tinha muita cobrança em cima de mim, tanto de produtividade quanto de proatividade para coisas que eu não sabia resolver no momento, em cima de mim. E essa cobrança, ela não era uma coisa que eu tinha um exemplo para eu seguir. A gerente me cobrava e ela não produzia também. Ela só mandava e ficava lá resolvendo as coisas dela sem querer ensinar nada" (E26).

A orientação para tarefas e resultados esperados diz respeito à definição clara de metas e papéis de trabalho, como observado nas falas de dois participantes:

"Quando você entra em um projeto e pensa que alguém ou esse líder vai te orientar, pelo menos em linhas gerais, dizer o que é esperado e quais os resultados esperados de um projeto" (E1).

“[...] por vezes a pessoa ignorava a minha situação, do tipo 'se vira', ou então pegava o caso para resolver, mas sem me explicar, sem me ajudar a esclarecer como eu poderia ter feito, entendeu? E isso fazia eu me sentir inferior, me sentir diminuída" (E27).

As habilidades relacionais referem-se a expectativas em relação à capacidade do líder de lidar com pessoas, manifestadas na forma de comunicar e ouvir, na civilidade e cortesia ao interagir com pessoas, e no reconhecimento e valorização dos membros de sua equipe:

“[...] passava informações de forma agressiva, demonstrando impaciência e intolerância, não considerando importante a valorização dos seus funcionários" (E2).

"[...] ela não sabia como agir, era grosseira, desrespeitadora e prepotente, além de nunca ouvir a sua equipe" (E13).

"Não tinha as competências necessárias para gerir uma equipe, além de não valorizar o departamento e os funcionários" (E15).

"Ele sempre chegava com histórias de 'eu fiz isso, eu fiz aquilo', só que para passar o trabalho, ele passava a maioria do trabalho dele para mim, e uma das coisas que mais me irritava eram os créditos. Ele não sabia falar na equipe. Ele só sabia falar dele" (E28). 
A ausência dos três atributos apresentados encontra ressonância na categoria de liderança ineficaz, especificamente no líder incompetente, como sugere Kellerman (2004). A inabilidade de se relacionar com as pessoas, assim como a ausência de orientação clara para tarefas e resultados parecem interferir de forma contundente na habilidade de liderar e, portanto, na percepção dos liderados acerca da má liderança. Além disso, a ineficácia da liderança é reforçada quando os liderados não percebem congruência entre os comportamentos do líder com aquilo que se espera dele, denominada neste estudo liderança pelo exemplo. A consideração dos três atributos apresentados sugere relações de baixa qualidade, como aborda a teoria LMX.

\subsection{Como é a Má Liderança?}

Nesta pesquisa, os participantes foram convidados a nomear livremente o tipo de má liderança que experimentaram, descrevendo esses líderes e seus comportamentos. Com base nas categorias preliminares, descrições associadas ou próximas foram reunidas em categorias mais amplas, até que se obtivesse uma lista abrangente, mas parcimoniosa, de dimensões da má liderança. Para melhor caracterizar essas dimensões, elas estão apresentadas sob a forma de tipologia, embora um mesmo líder possa ter apresentado comportamentos que se enquadram em mais de um tipo. São eles:

1) O Líder Incompetente: não possui conhecimento adequado, técnico ou do negócio para realizar seu trabalho e gerenciar seus subordinados. Também qualificado como despreparado pelos participantes.

"Se acha, mas não é... ele tinha dificuldade de argumentar, era impositivo, tinha pouco conhecimento técnico e do negócio" (E5).

"Eu achava que ele era ruim porque faltava muito conhecimento técnico, ele ficava muito vendido no assunto, me frustrava... nossa equipe acabava tendo uma imagem ruim diante das outras equipes, dando a impressão de que a gente não fazia nosso trabalho direito" (E22).

"As decisões tomadas por ele eram claramente inconsistentes. As vezes faltava lógica e bom senso. As vezes as ideias eram mirabolantes, e a gente não fazia a menor ideia porque ele tinha se fixado naquilo. E a gente perdia um tempo enorme tentando explicar, do ponto de vista técnico e gerencial, porque algo que ele queria não deveria ser feito" (E25).

2) O Líder Omisso: este tipo de líder não orienta e nem acompanha o trabalho da equipe, ou não fornece informações necessárias para a execução do trabalho. O líder não é claro sobre as metas individuais e da equipe, nem apoia a equipe. Não demonstra envolvimento ou comprometimento com o trabalho, ou demonstra não gostar de trabalhar. Além disso, é pouco acessível para esclarecimento de dúvidas. Também foi descrito como preguiçoso e enrolão pelos participantes.

"O que ele passa, ao menos para mim, é que não gosta de trabalhar e que ele quer uma equipe autossuficiente, que consiga tocar todos os projetos sem precisar dele, seja um analista júnior, sênior, pleno ou até estagiário. Assim, ele pode dedicar mais tempo para outras atividades como, acompanhar o Flamengo no campeonato de futebol, organizar o chope do fim de semana ou acompanhar a rotina dos filhos de forma instantânea" (E19).

"Ele só quer se dar bem. E aí deixa as coisas que não geram benefícios próprios imediatos de lado. Ele só quer se autopromover. Não defende o grupo" (E25).

"Ele me exigia muito, mas eu não tinha auxílio nenhum. Essa era a linha dele, de pegar as pessoas que conseguem fazer e explorar e sugar ao máximo" (E34).

3) O Líder Inconsistente: este tipo de líder é visto como contraditório e inconsistente porque transmite instruções ambíguas. Hesita em decidir, além de ser descrito como inseguro ou indeciso pelos participantes. 
"Você expõe uma ideia e ele dizia que tudo bem, ok, e depois ele queria alterar tudo, e depois não dava continuidade a essas alterações" (E1).

"Passava ordens divergentes para as pessoas da equipe, criando conflitos internos [...] criava situações negativas só para não se indispor com ninguém [...] tinha pouca disponibilidade de tempo" (E18).

"Ele exigia muito dos seus subordinados, mas não dava informações suficientes para as pessoas cumprirem as exigências dele; ele desconfiava das pessoas, tirava autonomia e depois sinalizava a falta de proatividade e cobrava a autonomia que ele mesmo não tinha dado" (E21).

4) O Líder Rígido: também chamado de centralizador e inflexível, impõe a sua forma de trabalhar sobre seus subordinados, não considerando suas necessidades ou pontos de vista.

"Era um impositivo, pois obrigava as pessoas a trabalharem da sua forma" (E9).

"As coisas funcionavam em torno dele, acho que o centro do trabalho, o centro de tudo era ele, parecia que não trabalhávamos para empresa, e sim para ele" (E20).

"Ele mantinha a empresa funcionando em função dele, sabe? O funcionário querendo ir embora e $1 \mathrm{~h}$ da manhã, ele prendia o funcionário lá só para ficar servindo ele" (E32).

5) O Líder Abusivo: o líder se relaciona de maneira agressiva com a equipe. Repreende de forma agressiva a ação de um funcionário, causando constrangimento para todos os presentes. Também chamado de líder agressivo e tirano.

"Eu e todos do grupo ficávamos com medo de errar, ele chamava a atenção e dava 'esporro' na frente de todo mundo e, ainda que fosse de forma reservada, ele falava em um tom agressivo, sempre com o objetivo de repreender e não em um sentido construtivo" (E23).

"Conviver com o líder era uma angústia constante. A gente nunca sabia quando ele ia se exaltar, berrar, dar um murro na mesa" (E24).

"O líder era uma pessoa desequilibrada emocionalmente, sem nenhuma inteligência emocional, desagregador, péssimo em termos de feedback" (E25).

"Ele tem um jeito meio explosivo. De vez em quando ele dá umas surtadas e aí grita... as vezes ele não entende o que está acontecendo com a gente. Ele trata a gente como se tivesse fazendo um favor para a gente, sabe?" (E35).

6) O Líder Desleal: o líder prejudica o trabalho da sua equipe. Não é abertamente agressivo, mas mente, engana e omite informações. Age com falsidade e desvaloriza ou sabota os membros da sua equipe. Também chamado de líder kamikaze e falso.

“A impressão que ele passava é que queria se autodestruir, não fazia nada pela equipe e pelas vendas. Parecia que queria destruir a empresa, de alguma forma, o trabalho da empresa" (E8).

"Para alcançar seus interesses, manteve as pessoas sobrecarregadas, prometeu promoções que nunca existiram além de dificultar e esconder oportunidades na empresa" (E14).

"Ele inventava coisas para o superior dele sobre mim... ficava tipo uma fofoca. E eu fiquei sabendo disso. Aquilo me magoou muito, porque você não faz isso, você é profissional” (E30).

"Tratava as questões da empresa como se fossem pessoais, levava tudo para o lado pessoal. Era desonesto e vingativo" (E25).

É possível identificar dentre os tipos levantados as duas orientações relacionadas à má liderança, uma mais associada às competências de liderança, e a outra relacionada ao caráter do líder, como proposto na literatura (CIULLA, 2004; KELLERMAN, 2004). Dentro do primeiro grupo, a má liderança é caracterizada pelos entrevistados como má não apenas pelo líder não demonstrar ter competências necessárias para cumprir seu papel e estabelecer um bom fluxo de trabalho a partir de um relacionamento produtivo com sua equipe, mas também por apresentar características pessoais que afetam negativamente o trabalho e os liderados, 
como apatia, insegurança e intransigência. Neste estudo, é no nicho da ineficácia que aparecem o maior número de dimensões (Incompetente; Omisso; Inconsistente; Rígido). No que se refere ao desvio de caráter ou fraqueza moral, neste estudo aparecem relatos de lideranças que engajam em ações intencionalmente destrutivas que provocam prejuízos diretos sobre a equipe e a organização (Abusivo; Desleal).

\begin{tabular}{|c|c|}
\hline Tipo & Definição \\
\hline Líder incompetente & Não possui conhecimentos técnicos ou do negócio. \\
\hline Líder omisso & Não demonstra compromisso com o trabalho; não orienta nem acompanha. \\
\hline Líder inconsistente & Incoerente e ambíguo; transmite instruções contraditórias. \\
\hline Líder rígido & $\begin{array}{c}\text { Impõe sua forma de trabalhar sobre os outros; desconsidera diferentes } \\
\text { necessidades e pontos de vista. }\end{array}$ \\
\hline Líder abusivo & Se relaciona de forma rude ou verbalmente violenta; constrange a equipe. \\
\hline Líder desleal & Sabota a organização e o trabalho; é desonesto; omite informações. \\
\hline
\end{tabular}

Quadro 2. Tipos de Má Liderança.

Fonte: Elaborado pelos autores.

Os tipos categorizados como líder omisso e líder inconsistente remontam a liderança considerada negligente ou laissez-faire. Além de estar associada à passividade e inabilidade de atuação do líder (CRAIG e KAISER, 2013), esses líderes contribuem para que existam conflitos e ambiguidade nas tarefas (SKOGSTAD et al., 2007). A ausência ou aparente contradição nas orientações dadas aos liderados parece salientar a percepção de incompetência e má liderança.

O traço de personalidade narcisista, marcado pela arrogância, egocentrismo, hostilidade e percepção dos outros como inferiores (ROSENTHAL e PITTINSKY, 2006; O'REILLY III, DOERR e CHATMAN, 2018) encontra eco nos líderes categorizados como rígido e abusivo. Se por um lado, o líder rígido não considera as perspectivas de seus funcionários, o que pode estar associada a visão exagerada de seu próprio valor, por outro, a agressividade pode também povoar suas relações. O líder abusivo é tóxico e fere o bem-estar de pessoas com as quais se relaciona não tolerando, por exemplo, o sucesso de outros que possam se destacar mais do que o mesmo (LUBIT, 2002).

Os relatos sobre o líder desleal descrevem comportamentos manipuladores e insensíveis, também sugestivos de elementos que caracterizam a "tríade escura" (dark triad) narcisismo, maquiavelismo e psicopatia (PAULHUS e WILLIAMS, 2002). Ao descreverem a sua relação com esses líderes, os entrevistados manifestaram visível sofrimento, o que será apresentado a seguir.

\subsection{Quais os Impactos da Má Liderança?}

\subsubsection{Na Relação Líder-Subordinado}

A perda de motivação foi recorrente nas falas dos entrevistados, acompanhada pelo sentimento de insegurança, frustração e desânimo.

"Você não quer trabalhar. Por quê você vai se desgastar com um chefe que é assim, desse jeito? Isso desmotiva a pessoa, muito. Não dá vontade nenhuma de ir trabalhar" (E32). 
"Muitas vezes, antes de sair de casa, já pensava que meu dia ia ser ruim" (E8).

"As pessoas estavam sempre desmotivadas, inclusive eu, além de não terem perspectiva nenhuma de se manter na empresa e crescer junto com ela" (E6).

“[...] além de sentir muita raiva dele por não me orientar, não me agregar como profissional e me abandonar no dia a dia do trabalho, desde o início da minha trajetória nessa empresa" (E19).

É possível concluir que a má liderança impacta, de forma imediata, o envolvimento e o engajamento com o trabalho. Além disso, ela tem consequências para a relação entre líder e liderado. As relações dos entrevistados com seus líderes refletem maior ou menor grau de conflito, podendo ser caracterizadas por um relacionamento pacífico, mas superficial para evitar atritos, até relações mais conflituosas e corrosivas.

"Virou uma pessoa em quem eu não me espelhava e não tinha vontade de trabalhar" (E12).

"Eu evitava me aproximar dele, falando somente o necessário" (E7).

"Quando eu fui conhecendo ele, eu notava o humor dele e sabia se eu podia perguntar ou não, algumas vezes deixava as coisas escritas na mesa dele para não estar incomodando muito, as vezes preferia tirar as dúvidas por telefone porque aí ele era um pouco mais simpático" (E21).

"Eu batia de frente contra ele sendo sarcástico, apenas assim" (E29).

\subsubsection{Na Equipe}

A partir dos relatos mencionados é possível verificar que além do impacto na própria relação líder-liderado, há impactos na imagem, desempenho e produtividade das equipes:

"Ele era líder porque estava no organograma; a equipe era altamente desmotivada, uma equipe que acabava refletindo essas resistências dele não buscava melhorar os processos, não buscava autonomia, não flexibilizava nada, as pessoas estavam lá porque não tinham outra opção” (E20).

"Afastamento da equipe, desmotivação, perda de agilidade na execução do trabalho, entrega de soluções básicas, insatisfação do cliente e retrabalho" (E9).

"Todo mundo tinha medo dele, quando ele chegava as pessoas mudavam de comportamento... todo mundo se limitava a fazer só o que era solicitado, sem sugerir muitas coisas novas" (E23).

"A equipe acabava tendo uma imagem ruim diante das outras equipes, uma impressão de que a gente não fazia nosso trabalho direito" (E22).

Além da desmotivação, foram citadas a desintegração das pessoas, falta de senso de equipe, problemas de relacionamento, ausência de desenvolvimento das pessoas, falta de transmissão de conhecimento, sobrecarga e perda de agilidade na execução do trabalho.

\subsubsection{No Trabalho}

O resultado do trabalho também é impactado pela má liderança, embora vários relatos indiquem comprometimento com a execução do próprio trabalho mesmo em condições adversas. Os participantes apontam também para a possibilidade de melhores resultados caso tivessem uma liderança diferente:

"[...] fiz um bom trabalho independente de ter ou não uma liderança" (E13).

"[...] eu trabalhava tensa o tempo todo, sem saber se o que estava fazendo era certo ou errado" (E6).

"Eu acredito que realmente tinha potencial para exercer o trabalho, mas não conseguia exercer cem por cento, fui limitado pela falta de informações e receio de fazer alguma coisa e ser condenado por aquilo; algumas vezes eu não sabia quando e como agir" (E21).

“[...] mas se as expectativas em relação ao meu trabalho estivessem claras eu atingiria melhores resultados" (E18).

"Acabava que não fazia o meu melhor, nunca ia além com medo de represálias" (E23). 
Os relatos dos entrevistados sugerem que há impactos negativos da má liderança na execução do trabalho, como questões relacionadas ao retrabalho, perda de qualidade, atraso no cronograma e dificuldades em fechar negócios. Essas observações sugerem que há, portanto, consequências para a produtividade e desempenho da própria organização. Especificamente, foram mencionadas pelos participantes perdas na imagem da empresa e alta rotatividade:

"O trabalho não fluía e não era entregue de forma tão ágill" (E9).

"Em negócios praticamente fechados, quando ele entrava, muitas vezes inviabilizava que aquele negócio se concretizasse" (E8).

"Ele perdeu muita gente boa... as pessoas não aguentavam... para empresa isso era péssimo porque depois tinha que contratar e treinar, tudo novamente" (E18).

Cabe mencionar também a estreita relação da má liderança com um clima organizacional ruim, marcado pela insatisfação, estresse e tensão, o que corrobora os achados de Krasikova, Green e Lebreton (2013), que salientam ineficiência, fracasso no alcance de metas e recorrência de problemas legais nos contextos marcados pela liderança tóxica.

“Trabalhar num local assim era brabíssimo. O que impacta é que eu tive gastrite nervosa, porque para ir trabalhar você não tem vontade de trabalhar. Você vai mesmo assim porque precisa, mas sabe que vai ter aquela pressão, aquela coisa desnecessária e assim tocava-se o barco" (E32).

"Isso começou a desgastar bastante a minha saúde, andava muito estressada, e aí me estressava mais ainda não poder fazer meu trabalho do jeito que eu gosto" (E31).

\subsection{Estratégias de Reação}

Os participantes relataram a adoção de diferentes estratégias com o objetivo de lidar com o mau líder. De saída, a má liderança parece colocar à prova as virtudes dos liderados:

"Diversas 'estratégias' [risos] como paciência, subordinação, controle emocional, equilíbrio, compreensão, flexibilidade” (E2).

"Em geral, manter a calma e ter muita paciência" (E3).

No entanto, as reações tendem a ser não-cooperativas (THOMAS, 1992). O evitamento, através do afastamento psicológico ou físico, foi a reação mais frequentemente mencionada pelos participantes para lidar com a má liderança, com consequências para a rotatividade voluntária na equipe e na empresa. Os relatos sugerem que há variedade na intensidade do afastamento, que pode ser caracterizado por um estado mental de distanciamento e indiferença sobre o trabalho, até o afastamento concreto, na forma de transferências internas e saída voluntária da empresa, sendo esta a estratégia mais comum:

"Como eu tinha outras coisas para fazer fora desse projeto, não era difícil, porque era fácil botar todo meu tempo e energia nesses outros trabalhos e fazer o mínimo dentro do projeto" (E1).

"[...] assim que surgiu uma oportunidade em outro cargo, eu não hesitei em aceitar, hoje sou bem mais realizada!" (E13).

“[...] e quando apareceu a oportunidade de largar essa área de gerenciamento de projeto e ser transferido para outra função, para mim foi um escape bom, e saí e confesso a você: 33 anos de companhia e foram meus últimos três melhores anos" (E34).

“[...] a situação só melhorou quando falei que gostaria de pedir demissão e um ano depois, mudei de projeto" (E14).

"Eu não aguentei, pedi demissão" (E22).

Embora menos frequente, alguns participantes mencionaram estratégias de confrontamento/competição, através de queixas junto aos superiores, na área de Gestão de 
Pessoas ou mesmo na justiça. Medidas formais foram citadas, como, por exemplo, a documentação de toda ordem recebida pelo mau líder a fim de comprovação futura.

"Eu tentava documentar tudo por escrito, cada desmando ou ameaça. Nem tudo eu tinha por escrito. Parece que ele escolhia a hora certa de fazer ameaças. Eu cheguei a consultar um advogado para me orientar" (E25).

"Eu nunca me intimidei com essa situação. Na verdade, eu sempre batia muito de frente. Eu discutia... inclusive, teve situações em que eu pulava a hierarquia e ia falar com outros superiores a ela" (E31).

Alguns participantes mencionaram a busca de suporte externo e a tentativa de obter apoio a partir de terapia, meditação e foco em atividades como o estudo, para reduzir a ansiedade e a frustração provocadas pelas lideranças tóxicas.

"A terapia me ajudou muito nesse processo... procuro desenvolver a automotivação. Também busquei a yoga para trazer mais equilíbrio, paz e, principalmente, tentar diluir esse sentimento de raiva provocado dentro do ambiente de trabalho" (E19).

\section{Considerações Finais}

Ainda que a liderança seja normalmente tratada como um fenômeno inerentemente positivo, esta pesquisa endossa a premissa de que, dentro de estruturas formais de gestão, aqueles designados a exercer o papel de líder podem ter uma atuação tóxica, o que coloca em risco o desempenho das equipes e da própria organização. As observações desta pesquisa sugerem que existem expectativas sobre o papel de líder que, uma vez insatisfeitas, tenderão a provocar reações negativas nas atitudes e comportamentos dos liderados. Destacam-se: (1) a capacidade de estabelecer metas e clarificar os papéis de seus liderados; (2) as capacidades sócio-relacionais; e (3) a integridade entre o discurso e o comportamento do líder.

Essa investigação envolveu o alcance dos três objetivos inicialmente propostos. $\mathrm{O}$ primeiro refere-se à caracterização das dimensões da má liderança mais frequentemente observadas nas organizações, o segundo a identificação e análise dos principais impactos da má liderança no ambiente de trabalho, e o terceiro a identificação das principais estratégias de reação adotadas para lidar com a liderança tóxica no contexto brasileiro.

A análise das dimensões da má liderança reforça as proposições de Kellerman (2004), ao apontar para duas expressões centrais da má liderança: a liderança ineficaz e a liderança imoral. Porém, os seis arquétipos da liderança ineficaz observados neste estudo em parte se distinguem daqueles descritos por Kellerman (2004), possivelmente pelo foco desta pesquisa se concentrar na liderança no ambiente corporativo e, em diferentes níveis gerenciais. Com base nos relatos dos entrevistados, foram delineados quatro tipos de má liderança associadas à ineficácia: o líder incompetente, omisso, inconsistente e rígido. Além da falta de competências técnicas (incompetente) e da incapacidade de mudar quando necessário (rígido), emergiram duas dimensões de má liderança associadas à ineficácia: a negligência/inércia no desempenho do papel (omisso) e a ambiguidade no processo decisório (inconsistente). Já as dimensões associadas à imoralidade se diferenciaram das de Kellerman (2004) ao se concentrarem em dois tipos: a conduta interpessoal agressiva (abusivo) e a conduta interpessoal desonesta (desleal).

O segundo objetivo foi alcançado por meio da identificação e análise dos principais impactos da má liderança no ambiente de trabalho, em três dimensões: relações entre líder e liderados, trabalho e organização. Independente da atribuição feita ao líder, ineficaz ou imoral, as relações estabelecidas entre o mau líder e seus liderados são sempre de baixa qualidade, impactando consequentemente a execução do trabalho, as dinâmicas da equipe e a própria organização. Nesse sentido, a pesquisa sugere que a má liderança pode chegar a colocar toda a equipe no out-group do líder, quando os membros se limitam aos papéis e 
responsabilidades definidos, sem exercer esforço para realizar além do que foi solicitado ou previamente estabelecido. Dessa maneira, a baixa moral da equipe tem impacto sobre a motivação para o trabalho e o engajamento, afetando a produtividade e a qualidade do trabalho, tal como observado nos estudos sobre líderes negligentes (SKOGSTAD et al., 2007).

Segundo os entrevistados, o grupo de trabalho sofre também com a ausência de espírito de equipe e a alta rotatividade, além de adquirir uma má reputação junto às demais áreas da organização, em linha com os achados de estudos internacionais sobre a supervisão abusiva (DUFFY, GANSTER e PAGON, 2002; TEPPER, 2000). Notadamente, emoções como insegurança, medo, frustração e raiva foram citadas como obstáculos à realização de um bom trabalho, sendo observadas experiências associadas ao estresse. Tal como constatado por Harms et al. (2017), há indícios de que a má liderança pode impactar o bem-estar físico e mental dos empregados. Para a organização, há impactos relevantes, particularmente a alta rotatividade e custos com recrutamento e treinamento, ausência ou diminuição de comprometimento, com consequências para o clima organizacional, o compartilhamento de conhecimento e a colaboração (KRASIKOVA, GREEN e LEBRETON, 2013; LEE, KIM e YUN, 2018).

Não é surpreendente, portanto, que os mecanismos de reação dos trabalhadores observados, terceiro objetivo proposto nesse estudo, sejam tipicamente não-cooperativos e adversos para a organização, sejam eles passivos (desengajamento) ou ativos (saída da equipe e da organização ou ações na justiça). Predominantemente, os relatos sugerem distanciamento, evitamento e indiferença, que podem variar de um estado mental desconectado do trabalho até o afastamento físico definitivo, como a saída da organização. Também foi relatada a busca por mecanismos externos de regulação, como a meditação e prática de yoga.

Para a comunidade acadêmica nacional, este estudo amplia o debate acerca da má liderança avançando em um campo do conhecimento ainda pouco explorado (ANDRADE et al., 2019; ABELHA e CAVAZOTTE, 2016). A discussão sobre as três dimensões afetadas por maus líderes, indivíduo, equipe e organização, contribui para uma perspectiva mais integradora e dinâmica a respeito da liderança, trazendo o contexto e os seguidores como elementos igualmente importantes quando comparados ao líder na gênese da má liderança (KELLERMAN, 2013). No que se refere às implicações gerenciais, reforça-se a relevância do tema, contribuindo para o desenvolvimento de programas de capacitação e formação de líderes com a problematização de situações reais, como aquelas levantadas neste estudo.

Dentre algumas limitações do estudo se destacam o conjunto relativamente pequeno de participantes, concentrado no estado do Rio de Janeiro, bem como limitações do método, que impedem que se estabeleça relações particulares entre as diferentes dimensões da má liderança e suas consequências específicas para as relações de trabalho e para os resultados organizacionais. Assim, novas pesquisas de natureza inferencial poderiam investigar mais profundamente o impacto de diferentes tipos de má liderança nos três níveis (indivíduo, equipe e organização). Novas pesquisas poderiam também explorar as seis dimensões aqui delimitadas, buscando analisar a predominância das dimensões mapeadas neste estudo em áreas ocupacionais ou indústrias específicas, bem como o delineamento de novas dimensões. As crises recentes associadas à má liderança em organizações públicas e privadas brasileiras reforçam a importância de estudos futuros para aprofundar a identificação das facetas da má liderança, mas sobretudo para melhor investigar suas causas.

Embora este estudo contribua para o desenvolvimento da boa liderança ao esclarecer aspectos críticos associados às ações de maus líderes e os principais vícios a serem coibidos, eliminar a má liderança ou mitigar seus impactos é uma missão desafiadora. Quando líderes estabelecem objetivos claros e destrutivos para a organização, a probabilidade da má 
liderança ser notada e cessada pela alta administração é maior. Porém, desafios mais complexos se colocam quando líderes destrutivos alcançam objetivos organizacionais utilizando métodos de influência tóxicos. Como esses líderes entregam resultados, as organizações podem tolerar ou até encorajar esse tipo de liderança (CRAIG e KAISER, 2013; HARMS et al., 2018). Não é surpreendente, portanto, que mecanismos de reação dos trabalhadores observados neste estudo sejam tipicamente não-cooperativos e adversos para a empresa, sejam eles passivos (desengajamento) ou ativos (saída da equipe e da organização; ações na justiça). Organizações que almejam de fato restringir a má liderança devem buscar soluções levando em conta a assimetria de poder inerente às estruturas gerenciais, e se posicionar de forma incisiva quando os líderes se comportarem de maneira tóxica.

\section{REFERÊNCIAS}

ABELHA, D. M.; CAVAZOTTE, F. S. C. N. O impacto das emoções de um líder inautêntico na percepção de seus seguidores. XIX SemeAd - Seminários em Administração - FEAUSP. ISSN: 2177-3866, 2016.

ANDRADE, P. C.; ROSÁRIO, R. A.; MOREIRA, T. A. P.; NETO, A. C. R. A incidência de liderança tóxica em uma empresa multinacional do setor de call center. Revista de Carreiras e Pessoas (ReCaPe), v. 9, nº 3, p. 376-392, 2019.

AVOLIO, B. Full leadership development: building the vital forces in organizations. Thousand Oaks: Sage, 1999.

AVOLIO, B.; BASS, B.; JUNG, D. Re-examining the components of transformational and transactional leadership using the Multifactor Leadership Questionnaire. Journal of Occupational and Organizational Psychology. v. 72, p. 441-462, 1999.

AVOLIO, B.; GARDNER, W.; WALUMBWA, F.; LUTHANS, F; MAY, D. Unlocking the mask: A look at the process by which authentic leaders impact follower attitudes and behaviors. The Leadership Quarterly, v. 15 (06), p. 801-823, 2004.

AVOLIO, B.; GARDNER, W. Authentic leadership development: Getting to the root of positive forms of leadership. The Leadership Quarterly, 16, p. 315-338, 2005.

BASS, B. Leadership and performance beyond expectations. New York: Free Press, 1985.

BASS, B.; AVOLIO, B. Developing Transformational Leadership: 1992 and Beyond. Journal of European Industrial Training, v. 14, p. 20-27, 1990.

BASS, B.; AVOLIO, B. Transformational leadership: a response to critiques. In M. M. Chemmers e R. Ayman (Eds), Leadership theory and research: perspectives and directions, pp. 49-88, San Diego: Academic Press, 1993.

BASS, B.; AVOLIO, B. Improving organizational effectiveness through transformational leadership. Thousand Oaks, CA: Sage, 1994.

BASS, B.; STEIDLMEIER, P. Ethics, character, and authentic transformational leadership behavior. The Leadership Quarterly, v. 10 (02), p. 181-217, 1999.

BARDIN, L. Análise de Conteúdo. São Paulo: Edições 70, 2011.

BURNS, J. M. Leadership. In: Transactional and transforming leadership. New York: First Harper Paperback, 1978. 
CAVAZOTTE, F. S. C. N.; DUARTE, C. J. P.; GOBBO, A. M. C. Líder autêntico, trabalho seguro: a influência da liderança sobre o desempenho em segurança. Brazilian Business Review (BBR), 10 (2), p. 97-123, 2013.

CAVAZOTTE, F. S. C. N.; MORENO, V.; BERNARDO, J. Transformational leaders and work performance: the mediating roles of identification and self-efficacy. Brazilian Administration Review (BAR), 10 (4), p. 490-512, 2013.

CAVAZOTTE, F. S. C. N.; MORENO, V.; LASMAR, L. C. Enabling customer satisfaction in call center teams: the role of transformational leadership in the service-profit chain. The Service Industries Journal, p. 1-14, 2018.

CIULLA, J. B. What is Good Leadership? Leadership Magazine, John F. Kennedy School of Government for Public Leadership, Harvard University: Forthcoming, 2004.

CRAIG, S.; KAISER, R. Destructive Leadership. In: Rumsey, M. The Oxford Handbook of Leadership. New York: Oxford University Press, 2013.

CRESWELL, J. Projeto de pesquisa: métodos qualitativo, quantitativo e misto. Artmed, 2010.

DIHN, J. E; LORD, R. G.; GARDNER, W. L.; MEUSER, J. D.; LIDEN, R. C.; HU, J. Leadership theory and research in the new millennium: Current theoretical trends and changing perspectives. The Leadership Quarterly, 25(1), 36-62, 2014.

DUFFY, M.; GANSTER, D.; PAGON, M. Social undermining in the workplace. Academy of Management Journal, v. 45, p. 331-351, 2002.

ESPER, A. J. F.; CUNHA, C. J. C. A liderança autêntica: uma revisão integrativa. Revista NAVUS, v. 5, n 2, p. 60-72, 2015.

EXAME. Corrupção na Odebrecht é a mais organizada da história do capitalismo. Disponível em: https://exame.abril.com.br/negocios/corrupcao-na-odebrecht-foi-a-maisorganizada-da-historia-do-capitalismo/. Acesso em: 20 de dezembro de 2019.

GARDNER, W. L.; AVOLIO, B. J.; LUTHANS, F.; MAY, D. R.; WALUMBWA, F. Can you see the real me? A self-based model of authentic leader and follower development. The Leadership Quarterly, v.16, p.343-372, 2005.

GEORGE, B.; SIMS, P.; MCLEAN, A. N.; MAYER, D. Discovering your authentic leadership. Harvard Business Review, 85(2), 129, 2007.

GRAEN, G. B.; UHL-BIEN, M. The Relationship-based approach to leadership: Development of LMX theory of leadership over 25 years: Applying a multi-level, multidomain perspective. The Leadership Quarterly v. 6 (2): 219-247, 1995.

HARMS, P. D.; CREDÉ, M.; TYNAN, M.; LEON, M.; JEUNG, W. Leadership and stress: A meta-analytic review. The Leadership Quarterly, v. 28, p. 178-194, 2017.

HARMS, P. D.; WOOD, D.; LANDAY, K.; LESTER, P. B.; LESTER, G. V. Autocratic leaders and authoritarian followers revisited: A review and agenda for the future. The Leadership Quarterly, v. 29, p. 105-122, 2018.

HOUSE, R.; SPANGLER, W.; WOYCKE, J. Personality and charisma in the U.S. Presidency: A psychological theory of leader effectiveness. Administrative Science Quarterly, v. 36, p. 364-396, 1991. 
INNESS, M.; BARLING, J.; TURNER, N. Understanding supervisor-targeted aggression: A within-person, between-jobs design. Journal of Applied Psychology, v. 90, p. 731-739, 2005.

JUDGE, T.; PICCOLO, R. Transformational and transactional leadership: A meta-analytic test of their relative validity. Journal of Applied Psychology, v. 89, p. 755-768, 2004.

KELLERMAN, B. Bad leadership: what it is, how it happens, why it matters. Boston: Harvard Business School Press, 2004.

KELLERMAN, B. Leading questions: The end of leadership - redux. Leadership, v. 9 (1) pp. 135-139, 2013.

KRASIKOVA, D.; GREEN, S.; LEBRETON, J. Destructive Leadership: A Theoretical Review, Integration, and Future Research Agenda. Journal of Management, v. 39(5), 13081338, 2013.

LEE, S.; KIM, S. L.; YUN, S. A moderated mediation model of the relationship between abusive supervision and knowledge sharing. The Leadership Quarterly, v. 29, p. 403-413, 2018.

LIANG, L.; BROWN, D. J.; LIAN, H., HANIG, S.; FERRIS, D. L.; KEEPING, L. M. Righting a wrong: Retaliation on a voodoo doll symbolizing an abusive supervisor restores justice. The Leadership Quarterly, v. 29, p. 443-456, 2018.

LIDEN, R; WAYNE, S.; STILWELL, D. A. Longitudinal study on the early development of leader-member exchanges. The Journal of Applied Psychology, 78, pp. 662-674, 1999.

LOWE, K.; KREOCKE, K.; SIVASUBRAMANIAM, N. Effectiveness correlates of transformation and transaction leadership: a meta-analytic review. The Leadership Quarterly, v. 7, pp. 385-425, 1996.

LUBIT, R. O Impacto dos Gestores Narcisistas nas Organizações. Revista de Administração de Empresas (RAE), v.42. n.3, p.66-77, 2002.

LUCENA, J. R. N.; CAVAZOTTE, F. S. C. N. Ethical leadership leader-follower relationship and performance: a study in a telecommunications company. Revista de Administração Mackenzie (RAM), 17 (2), p. 67-92, 2016.

LUTHANS, F.; AVOLIO, B. Authentic leadership: A positive developmental approach. In: CAMERON, K.; DUTTON, J.; QUINN, R. Positive organizational scholarship. San Francisco: Barrett-Koehler, 2003.

MISHLER, E. G. Research interviewing context and narrative. Cambridge, MA: Harvard University Press, 1986.

MITCHELL, M.; AMBROSE, M. Abusive supervision and workplace deviance and the moderating effects of negative reciprocity beliefs. Journal of Applied Psychology, v. 92, p. 1159-1168, 2007.

O'REILlY III, C. A.; DOERR, B.; CHATMAN, J. A. "See you in court": How CEO narcissism increases firm's vulnerability to lawsuits. The Leadership Quarterly, v. 29, p. 365-378, 2018.

PAULHUS, D. L.; WILliAMS, K. M. The Dark Triad of personality: Narcissism, Machiavellianism, and Psychopathy. Journal of Research in Personality, 36 (6): 556-5, 2002. 
PRATT, M. G. From the editors - For the lack of a boilerplate: tips on writing up (and reviewing) qualitative research. Academy of Management Journal, p. 856-862, 2009.

ROSENTHAL, S.; PITTINSKY, T. Narcissistic leadership. The Leadership Quarterly, v. 17, p. 617-633, 2006.

SHARMA, P. N. Moving beyond the employee: The role of the organizational context in leader workplace aggression. The Leadership Quarterly, v. 29, p. 203-217, 2018.

SILVERMAN, D. Interpreting qualitative data: methods for analyzing talk, text and interaction. Sage, 2006.

SKOGSTAD, A.; EINARSEN, S.; TORSHIEM, T.; AASLAND, M.; HETLAND, H. The destructiveness of laissez-faire leadership behavior. Journal of Occupational Health Psychology, v. 12, p. 80-92, 2007.

TEPPER, B. Consequences of abusive supervision. Academy of Management Journal, v. 43, p. 178-190, 2000.

TEPPER, B.; DUFFY, M., SHAW, J. Personality moderators of the relationships between abusive supervision and subordinates' resistance. Journal of Applied Psychology, v. 86, p. 974-983, 2001.

TURANO, L. M.; CAVAZOTTE, F. S. C. N. Conhecimento científico sobre liderança: uma análise bibliométrica do acervo do The Leadership Quarterly. Revista de Administração Contemporânea (RAC), 20(4), 434-457, 2016.

VALOR ECONÔMICO. Como CEOS veem a responsabilidade social e ambiental de suas empresas. Disponível em: https://valor.globo.com/carreira/recursos-humanos/coluna/comoceos-veem-a-responsabilidade-social-e-ambiental-de-suas-empresas.ghtml. Acesso em: 20 de dezembro de 2019.

WATKINS, T.; FEHR, R.; HE, W. Whatever it takes: Leader's perceptions of abusive supervision instrumentality. The Leadership Quarterly, v. 30, p. 260-272, 2019.

YUKL, G. A. Leadership in organizations, 5a Ed., Prentice-Hall, 2002. 